\title{
O MOVIMENTO ESCOTEIRO E A EDUCAÇÃO AMBIENTAL: ANÁLISE DA PRESENÇA DA EDUCAÇÃO AMBIENTAL NÃO-FORMAL EM UMA TROPA ESCOTEIRA EM PARANAGUÁ (PR)
}

Lucas Lahoni Soares Raposo ${ }^{1}$

Allan Paul Krelling ${ }^{2}$

Izabel Carolina Raittz Cavallet ${ }^{3}$

Resumo: O Escotismo é um movimento norteado pela prática da educação nãoformal. A Educação Ambiental é atrativa para o Escotismo, visto que o mesmo busca desenvolver no jovem o respeito pela natureza. Este trabalho procurou identificar a presença dos princípios da Política Nacional de Educação Ambiental nas atividades desenvolvidas no Movimento Escoteiro. Elaborou-se um roteiro de observação quali-quantitativo de atividades escoteiras e observaram-se diretamente cinco diferentes atividades desenvolvidas no Grupo Escoteiro do Mar Ilha do Mel, situado no município de Paranaguá - PR. Os resultados indicaram que algumas atividades possuem um grande potencial para serem ferramentas de Educação Ambiental, enquanto outras não obtiveram o mesmo êxito.

Palavras-chave: Escotismo; Educação Ambiental; Movimento Escoteiro; Educação Não-Formal; Política Nacional de Educação Ambiental.

\footnotetext{
${ }^{1}$ Instituto Federal de Educação, Ciência e Tecnologia do Paraná. E-mail: lahoni.lucas@gmail.com.

2 Instituto Federal de Educação, Ciência e Tecnologia do Paraná. E-mail: allan.krelling@ifpr.edu.br.

3 Instituto Federal de Educação, Ciência e Tecnologia do Paraná. E-mail: izabel.cavallet@ifpr.edu.br.
} 


\section{Introdução}

O movimento escoteiro é um movimento educacional pautado na prática da educação não-formal incorporada por princípios que se estruturam nas chamadas "Lei e Promessa Escoteira". Possui atualmente em torno de 50 milhões de membros mundialmente e por ele já se estima que tenham passado mais de 250 milhões de pessoas (NAGY, 1985, p.195). Em nível nacional, o escotismo contava, em 2018, com um efetivo de mais de 100 mil membros, divididos em 687 municípios (ESCOTEIROS DO BRASIL, 2018, p. 22). Só no Paraná, se consolidaram 10 mil associados em 2017 (ESCOTEIROS DO BRASIL, 2018, p. 43). Portanto, é importante que estudos analisem esse movimento educacional sob um olhar científico e pedagógico, uma vez que a cada ano o movimento escoteiro torna-se mais presente em nossa sociedade e traz consigo um importante papel de formação cidadã. Pesquisas que abordem esses estudos apresentam-se relevantes, considerando-se a escassez de trabalhos que abordam o Movimento Escoteiro sob um olhar científico.

Especificamente no presente estudo, atribui-se ao Movimento Escoteiro o papel de ferramenta de Educação Ambiental (E.A.) segundo os princípios da Política Nacional de Educação Ambiental (PNEA). Paolillo (2009, p.96) já aponta a Educação Ambiental como um forte atrativo ao Escotismo, uma vez que este movimento traz dentro de seus interesses o estímulo no jovem do respeito pela natureza e compromisso com o Meio Ambiente, destacando a vida ao ar livre como valiosa experiência educativa.

\section{Revisão de literatura}

\section{O Escotismo}

Fundado em 1907 no Reino Unido por Lord Robert Stephenson Smyth Baden-Powell, o Escotismo pode ser definido como:

Um movimento educacional de jovens, sem vínculo a partidos políticos, voluntário, que conta com a colaboração de adultos, e valoriza a participação de pessoas de todas as origens sociais, etnias e credos, de acordo com seu Propósito, seus Princípios e o Método Escoteiro, concebidos pelo Fundador Baden-Powell e adotados pela União dos Escoteiros do Brasil. (ESCOTEIROS DO BRASIL, 2013, p.12).

O Movimento Escoteiro tem como propósito contribuir para que os jovens assumam seu próprio desenvolvimento, além de atingir suas plenas potencialidades físicas, intelectuais, sociais, afetivas e espirituais. (ESCOTEIROS DO BRASIL, 2017, p. 7)

Os princípios do Escotismo se baseiam nas chamadas "Lei e Promessa Escoteira", ideais morais que se flexibilizam e se ajustam aos progressivos graus de maturidade do indivíduo. Em função disso, são delimitados dentro do 
movimento por uma organização segundo faixa etária. Tal dinamicidade é caracterizada pela Organização em Ramos, tendo cada um deles um propósito educacional de acordo com a idade dos jovens que por eles estão passando. Existem quatro Ramos dentro do movimento escoteiro, sendo eles:

- Ramo Lobinho (abrangendo de 6,5 até 10 anos de idade);

- Ramo Escoteiro (abrangendo de 11 até 14 anos de idade);

- Ramo Sênior (abrangendo de 15 até 17 anos de idade);

- Ramo Pioneiro (abrangendo de 18 até 21 anos de idade).

O ponto de convergência entre as diversas atividades realizadas dentro desses ramos está no Método Escoteiro. O Método Escoteiro é um conjunto de pontos (ESCOTEIROS DO BRASIL, 2013, p.14) que garante que as atividades desenvolvidas dentro do movimento sejam condizentes com o Propósito e os Princípios do Escotismo, além de permitir uma avaliação sistemática nos mais variados níveis dentro do movimento. Esses pontos são:

1. Aceitação da Lei e da Promessa Escoteira;

2. Aprender Fazendo;

3. Vida em Equipe;

4. Atividades Progressivas, Atraentes e Variadas;

5. Desenvolvimento pessoal com Orientação Individual.

Por meio dessas ferramentas e características, o Escotismo se constrói como movimento educacional, e desempenha um papel ativo na nossa sociedade. Um desses casos é o da 1ํㅡ Guerra Mundial, onde jovens escoteiros ofereciam serviços voluntários em países e cidades atingidos pelos conflitos atuando como guardas, carteiros, doadores de sangue, etc. (NAGY, 1985, p. 75).

\section{A Política Nacional de Educação Ambiental}

A Política Nacional de Meio Ambiente (PNMA) traz consigo a finalidade de garantir "a preservação, melhoria e recuperação da qualidade ambiental à vida" (BRASIL, 1981). Para isso, nossa legislação aponta como um dos princípios da PNMA a "Educação Ambiental a todos os níveis de ensino, inclusive a educação da comunidade, objetivando capacitá-la para participação ativa na defesa do meio ambiente".

Segundo o Ministério do Meio Ambiente, a definição e as atribuições da Educação Ambiental enquanto ferramenta pedagógica e ambiental se dão segundo a lei 9795/1999, que institui a Política Nacional de Educação Ambiental (PNEA) e diz que:

Entendem-se por Educação Ambiental os processos por meio dos quais o indivíduo e a coletividade constroem valores sociais, conhecimentos, habilidades, atitudes e competências voltadas para a conservação do meio ambiente, bem de uso comum do povo, essencial à sadia qualidade de vida e sua sustentabilidade. 
A PNEA traz consigo oito princípios básicos em seu texto (no Art. $4^{\circ}$ de sua redação), pontos que podem ser interpretados como imprescindíveis para a caracterização da Educação Ambiental. Esses princípios são:

I - o enfoque humanista, holístico, democrático e participativo;

II - a concepção do meio ambiente em sua totalidade, considerando a interdependência entre o meio natural, o socioeconômico e o cultural, sob o enfoque da sustentabilidade;

III - o pluralismo de ideias e concepções pedagógicas, na perspectiva da inter, multi e transdisciplinaridade;

IV - a vinculação entre a ética, a educação, o trabalho e as práticas sociais;

V - a garantia de continuidade e permanência do processo educativo;

VI - a permanente avaliação crítica do processo educativo;

VII - a abordagem articulada das questões ambientais locais, regionais, nacionais e globais;

VIII - o reconhecimento e o respeito à pluralidade e à diversidade individual e cultural.

A Educação Ambiental pode aparecer em duas possíveis configurações segundo a PNEA: a Educação Ambiental formal e a Educação Ambiental nãoformal. A Educação Ambiental no aspecto formal se mostra nessa perspectiva como uma prática educativa integrada, contínua e permanente em todos os níveis de ensino formal (BRASIL, 1999), ocorrendo dentro de estabelecimentos de ensino formal (desde creches até universidades) e dentro dos parâmetros do ambiente acadêmico. Engloba assim as educações básica (Educação Infantil, Ensino Fundamental e Ensino Médio), superior, especial, profissional e de jovens e adultos. Apesar disso, a Educação Ambiental não é implantada como disciplina obrigatória em nenhum currículo de ensino dessas esferas da educação em nosso país, de forma a propor uma abordagem inter, multi e transdisciplinar (BRASIL, 1999).

Em posição diferente da E.A. formal (mas não necessariamente antagônica), a Educação Ambiental não-formal se apresenta no texto da PNEA como "o conjunto de ações e práticas educativas voltadas à sensibilização da coletividade sobre as questões ambientais e a sua organização e participação na defesa da qualidade do meio ambiente". Ou seja, a Educação Ambiental que não necessita acontecer dentro do ambiente acadêmico. Partindo da ideia da Educação não-formal do Movimento Escoteiro e as atribuições da PNEA para a Educação Ambiental não-formal, este trabalho traz como objetivo identificar a presença dos princípios da PNEA em atividades desenvolvidas dentro do Escotismo. 


\section{Objetivos}

\section{Objetivo geral}

- Identificar a presença dos princípios da PNEA em atividades desenvolvidas dentro do Movimento Escoteiro.

\section{Objetivos específicos}

- Observar e descrever cinco diferentes atividades desenvolvidas dentro de uma Tropa Escoteira;

- Identificar a presença da discussão sobre a temática ambiental nas atividades desenvolvidas no movimento escoteiro sob a ótica dos princípios da Política Nacional de Educação Ambiental;

- Definir como ocorre a Educação Ambiental dentro do Movimento Escoteiro.

\section{Materiais e Métodos}

Em consulta a projetos que identificassem diálogo entre o movimento escoteiro e a Educação Ambiental, observou-se escassez de pesquisas que tratassem do tema. Entre essas pesquisas, a maioria das publicações foi realizada pelos Escoteiros do Brasil.

Elaborou-se um roteiro quali-quantitativo de observação da presença de aspectos da Educação Ambiental não-formal em atividades desenvolvidas no Escotismo (ver apêndice 1). Na primeira parte (qualitativa) do roteiro, descreveuse a atividade analisada indicando o nome da atividade, o número de participantes, sua duração, material utilizado para sua execução e um resumo descritivo. Na segunda parte (quantitativa), criou-se uma escala de 0 a 5 (onde 0 representa que o princípio não estava presente e 5 que estava muito presente) para se valorar a presença de cada um dos oito princípios da PNEA (contidos no Art. $4^{\circ}$ da mesma) na atividade que se estava observando. Tal procedimento foi adotado, no intuito de que após a coleta de dados, os roteiros pudessem ser submetidos a análise comparativa, na geração de resultados quantitativos.

Em posse do roteiro, foi realizada a observação direta de atividades desenvolvidas pela Tropa Escoteira "Tadami Sato", do Grupo Escoteiro do Mar "Ilha do Mel", situado em Paranaguá, Paraná. A Tropa trabalha com o Ramo Escoteiro (11 a 14 anos) e durante o desenvolvimento deste trabalho, contava com um efetivo aproximado de 18 jovens. Para garantir a neutralidade da organização das atividades realizadas pela chefia da tropa, enviou-se uma carta solicitando autorização para a observação dentro de um período prédeterminado. Dessa forma, a chefia não ficaria ciente de quando as atividades seriam observadas. $\mathrm{E}$, os observadores não teriam ciência de quais atividades seriam realizadas, no período analisado. As atividades foram observadas em datas aleatórias, no período entre maio e agosto de 2018.

Por fim, os dados coletados foram tabulados e foram elaborados gráficos com os resultados presentes em cada atividade. Para a análise quantitativa, 
foram calculadas as médias simples dos resultados observados por atividades e da soma dos resultados de todas as atividades analisadas.

\section{Resultados e Discussão}

Pode-se observar na Tabela 1 um breve resumo das atividades desenvolvidas (Figura 1) ao longo da observação e seus resultados segundo o roteiro de observação elaborado.

Tabela 1: Descrição das atividades observadas e suas médias obtidas no roteiro de observação desenvolvido. Fonte: Dados coletados pelo autor.

\begin{tabular}{|c|c|c|c|}
\hline \multicolumn{2}{|r|}{ Atividade } & $\begin{array}{l}\text { Média atingida } \\
\text { (escala de } 0 \text { a } 5 \text { ) }\end{array}$ & Descrição \\
\hline 1 & $\begin{array}{l}\text { Instrução - } \\
\text { Montagem } \\
\text { de Campo } \\
\text { (Gráfico 1) }\end{array}$ & 3,75 & $\begin{array}{l}\text { Foi uma instrução para montagem de campo durante um } \\
\text { acampamento de baixo impacto realizado pela Tropa. } \\
\text { Aqui, os jovens receberam uma instrução para a } \\
\text { montagem de pioneirias, construções sustentáveis a } \\
\text { base de bambu. Participaram } 13 \text { jovens e a atividade teve } \\
\text { uma duração de } 3 \text { horas. }\end{array}$ \\
\hline 2 & $\begin{array}{l}\text { Instrução - } \\
\text { Montagem } \\
\text { de fossa } \\
\text { séptica } \\
\text { (Gráfico 2) }\end{array}$ & 3,88 & $\begin{array}{l}\text { Com a finalidade de diminuir os resíduos gerados no } \\
\text { acampamento, foi escavada uma abertura no solo do } \\
\text { terreno (de aproximadamente } 1 \mathrm{~m} \text { de profundidade). Nele, } \\
\text { depositava-se o lixo orgânico (restos de comida, borra de } \\
\text { café, etc.). Participaram } 13 \text { jovens e a atividade teve } \\
\text { duração de aproximadamente } 1 \text { hora. }\end{array}$ \\
\hline 3 & $\begin{array}{l}\text { Plantio de } \\
\text { árvores - } \\
\text { Mutirão de } \\
\text { Ação } \\
\text { Ecológica } \\
\text { (Gráfico 3) }\end{array}$ & 4,62 & $\begin{array}{l}\text { A atividade aqui foi um plantio de árvores realizado em } \\
\text { uma escola carente, situada na periferia do município de } \\
\text { Paranaguá. Dessa atividade participaram } 18 \text { jovens, e } \\
\text { teve duração de } 4 \text { horas. A atividade pode ser observada } \\
\text { na Figura } 1 .\end{array}$ \\
\hline 4 & $\begin{array}{l}\text { Atividade } \\
\text { náutica } \\
\text { (Gráfico 4) }\end{array}$ & 4,87 & $\begin{array}{l}\text { Nessa atividade, os jovens receberam instrução em terra } \\
\text { sobre a prática de Vela (esporte olímpico) e em seguida } \\
\text { realizaram uma atividade prática do mesmo conteúdo. } \\
\text { Pôde-se aqui observar o desenvolvimento do contato dos } \\
\text { jovens com o ambiente. Participaram } 10 \text { jovens, e ao todo } \\
\text { foram } 6 \text { horas de atividade. A mesma pode ser observada } \\
\text { na Figura } 2 \text {. }\end{array}$ \\
\hline 5 & $\begin{array}{l}\text { Jogo } \\
\text { Democrático } \\
\text { (Gráfico 5) }\end{array}$ & 4 & $\begin{array}{l}\text { Os jogos democráticos são atividades desenvolvidas ao } \\
\text { início de cada ciclo (período de } 6 \text { meses), onde os jovens } \\
\text { são incentivados a levar propostas de atividades que } \\
\text { queiram realizar junto à Tropa. Os critérios estipulados } \\
\text { pela Chefia eram que fossem definidos ao menos } 1 \\
\text { bivaque (atividade externa a sede com duração de } 1 \text { dia) } \\
\text { e } 1 \text { acampamento. Estiveram presentes } 17 \text { jovens e a } \\
\text { duração dessa atividade foi de } 3 \text { horas. }\end{array}$ \\
\hline
\end{tabular}




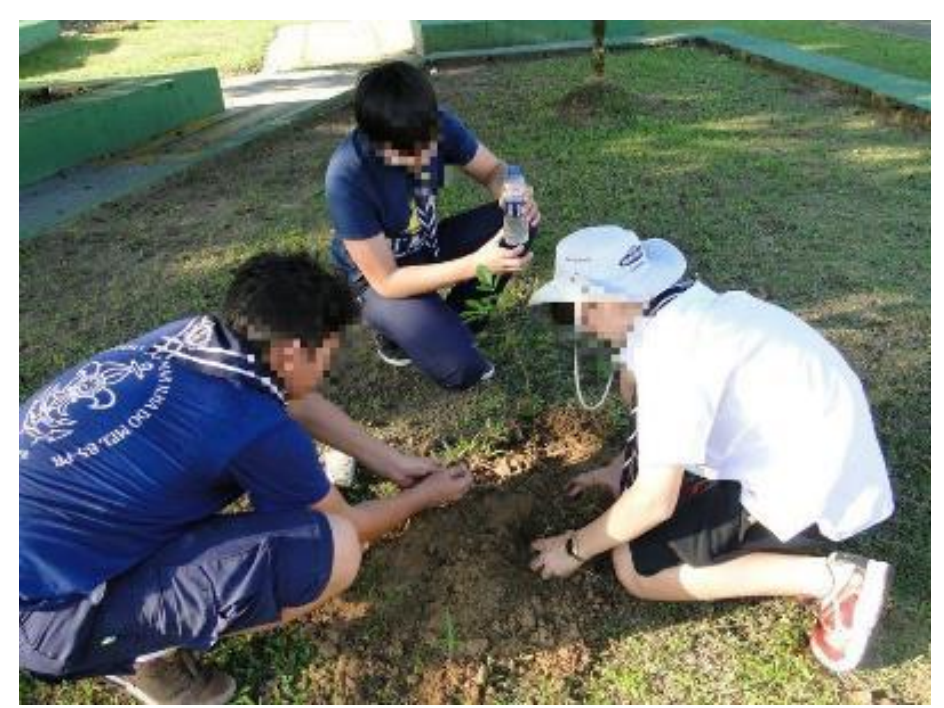

Figura 1: Atividade 3. Escoteiros realizando plantio de árvores Fonte: Grupo Escoteiro do Mar "Ilha do Mel". Acervo particular.

$\mathrm{Na}$ atividade 1 observou-se uma homogeneidade entre os princípios I, II e III, com um valor de 4/5 dentro da escala adotada. Já os princípios V, VI e VIII apresentam a mesma homogeneidade, mas com o valor de $5 / 5$ dentro da mesma escala. O princípio IV foi um pouco abaixo, apresentando o valor de $3 / 5$. O que chama a atenção na atividade 1 é o valor atribuído ao princípio VII. Apesar de ser um dos princípios que trata de temáticas exclusivamente ambientais, recebeu um valor igual a zero. Interpreta-se que isso seja devido ao fato da dificuldade de trazer na atividade descrita previamente a abordagem de questões ambientais em nível local, regional, nacional e global.

Já na atividade 2, nota-se um resultado muito similar, mas com uma diferença no princípio VII. Nesta atividade, identifica-se o cuidado com o impacto não somente local, mas também numa escala maior quando se pensa nos desdobramentos que o descarte indevido de resíduos pode acarretar.

$\mathrm{Na}$ atividade 3, obtiveram-se resultados altos dentro das atividades analisadas, ficando atrás apenas da atividade 4. Por se tratar de um Mutirão de Ação Ecológica já se esperava isso, devido ao fato de tal atividade ser pensada justamente para o desenvolvimento da visão dos jovens sobre a questão ambiental. A descrição da atividade conseguiu contemplar um resultado de 5/5 na maioria dos princípios, desde sua justificativa até sua execução. Somente os princípios IV (com valor de 4) e VI (com valor de 3) não atingiram tal marca, pois não foram totalmente identificados (numa perspectiva do observador) dentro da proposta da atividade. Foi possível observar o princípio IV (vinculação entre a ética, a educação, o trabalho e as práticas sociais) quando os jovens puderam observar a importância do que estavam realizando (aqui, uma tentativa de arborização em uma escola carente), e a forma como seu trabalho impactaria na realidade daquele espaço. Apesar disso, compreendeu-se que essa noção poderia ser melhor trabalhada dentro do programa da atividade (por exemplo: 
poderia haver um acompanhamento póstumo desse processo de arborização que os Escoteiros começaram). No caso do princípio VI, atribuiu-se o valor de 3 pois apesar de haver uma avaliação ao fim do evento, não se identificou a mesma ao longo de toda a atividade em questão.

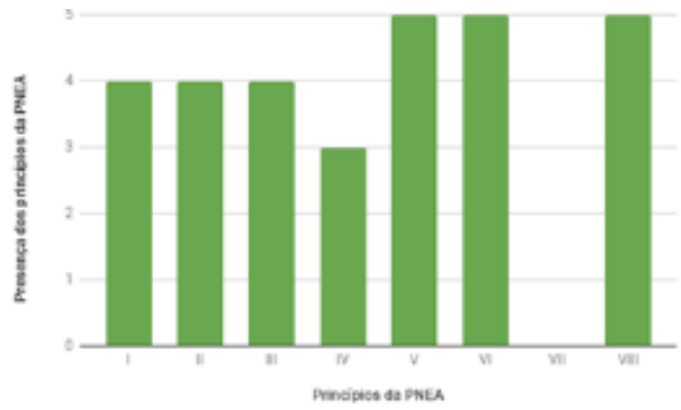

Gráfico 1: Presença dos 8 princípios da PNEA na atividade 1. Fonte: Dados coletados pelo autor.

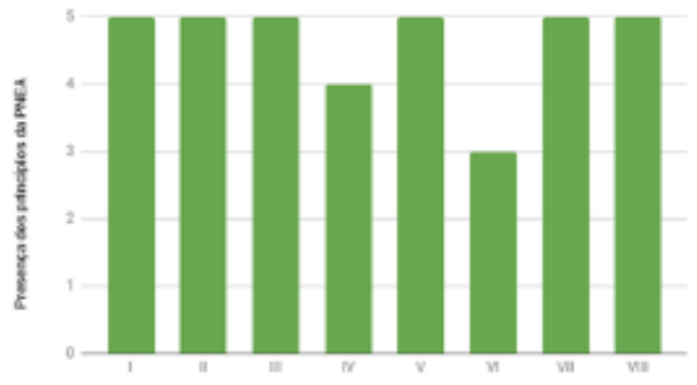

Pincoucs as PNEA

Gráfico 3: Presença dos 8 princípios da PNEA na atividade 3. Fonte: Dados coletados pelo autor.

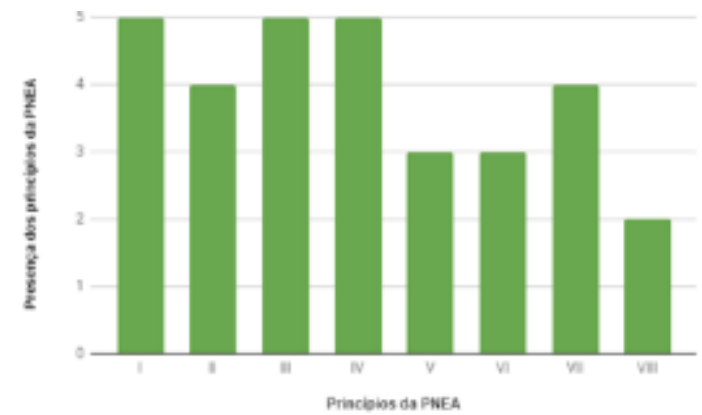

Gráfico 2: Presença dos 8 princípios da PNEA na atividade 2. Fonte: Dados coletados pelo autor.

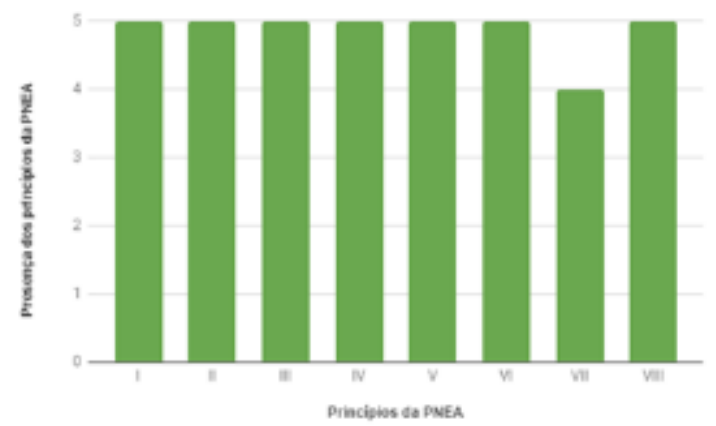

Gráfico 4: Presença dos 8 princípios da PNEA na atividade 4. Fonte: Dados coletados pelo autor.

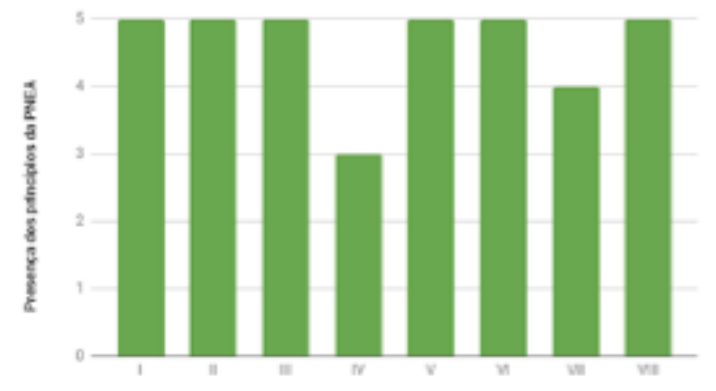

Gráfico 5: Presença dos 8 princípios da PNEA na atividade 5. Fonte: Dados coletados pelo autor.

A atividade 4 recebeu os valores mais altos dentro das atividades analisadas. Devido ao fato de nela os jovens estarem diretamente em contato com o ambiente e tomando noção de suas características e dos impactos da ação antrópica no mesmo, essa atividade conseguiu contemplar todas as 
características que a PNEA traz para a Educação Ambiental não-formal; desde os princípios até o caráter de sensibilização.

E por fim, observa-se na atividade 5 um resultado que aponta indiretamente a presença da E.A. não-formal. Ao estimularem os jovens a escolherem locais de contato próximo com a natureza (um dos critérios do Jogo Democrático) para suas atividades serem desenvolvidas, abriu-se caminho para imbuir o viés da sensibilização e dos princípios da PNEA, tendo em mente que aqui é a chefia da Tropa Escoteira que redigirá o programa educativo da atividade.

Podemos observar no Gráfico 6 a presença média dos 8 Princípios da PNEA nas atividades analisadas. Nota-se uma média geral com resultados (em sua maioria) acima de 4, destacando-se os princípios I e III com média 4,8. Em seguida, vem os princípios II e V, com a média de 4,6. Enquanto no princípio $\mathrm{V}$ fala-se sobre a garantia de continuidade e permanência do processo educativo, no princípio II já se abordam questões de um viés ambiental. Ele prevê a concepção do meio ambiente em sua totalidade, princípio a partir do qual já pode-se traçar uma discussão ambiental na atividade observada. Logo após, há o princípio VIII, com média 4,4. Este traz "o reconhecimento e o respeito à pluralidade e à diversidade individual e cultural". Apesar de não estar diretamente ligado à dimensão ambiental, é um indicador de como atuou a formação cidadã do movimento escoteiro dentro das atividades que foram observadas. $\mathrm{Na}$ sequência, vêm os princípios VI (com média 4,2), o princípio IV (com média 3,8) e o princípio VII (com média 3,4). Dentre estes, destaca-se o princípio VII. Este guia "a abordagem articulada das questões ambientais locais, regionais, nacionais e globais".

A presença dos princípios II e VII merecem atenção, pois são os únicos de cunho exclusivamente ambiental. $O$ que se pode perceber é que a presença da concepção de meio ambiente em sua totalidade (princípio II) é maior que a presença de uma abordagem articulada de questões ambientais em nível local, regional e global (princípio VII). Acredita-se que isso se deve ao fato de as atividades analisadas tratarem com um maior foco as questões em nível local, e consequentemente deixando de lado a articulação desses pontos com diferentes esferas (num viés geográfico).

A interpretação da forma como esses fatores aparecem indica que a Educação Ambiental não-formal está presente dentro das atividades analisadas (considerando o recorte feito e os parâmetros adotados) (Gráfico 6). 


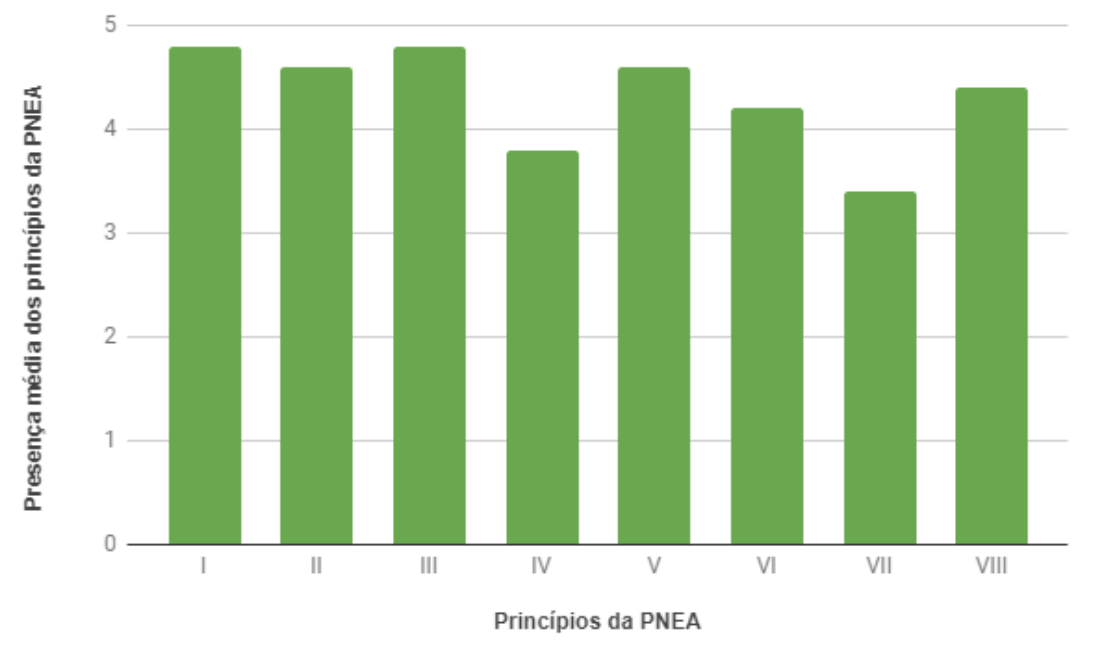

Gráfico 6: Presença média dos princípios da PNEA nas atividades analisadas. Fonte: Dados coletados pelo autor

Com base em tais resultados, enxerga-se no Movimento Escoteiro uma alternativa muito atraente no que diz respeito à formação cidadã com conscientização ambiental. Pôde-se visualizar nas atividades analisadas que o Escotismo abrange as questões ambientais de forma sutil, mas ainda assim com um olhar para a sensibilização que é proposta pela Educação Ambiental nãoformal segundo a PNEA.

\section{Conclusões}

Conclui-se neste trabalho que a Educação Ambiental não-formal está presente no Movimento Escoteiro, considerando o ramo escoteiro. Observa-se, contudo, que esta conclusão se embasa na análise de cinco atividades.

Observou-se no Movimento Escoteiro a presença de todos os componentes necessários para a aplicação da Educação Ambiental não-formal como ferramenta pedagógica de sensibilização. Inclusive, ela se mostra muitas vezes como atrelada ao estilo de vida que o Escotismo propõe. Percebeu-se também que algumas atividades possuem um potencial maior para dialogar com o texto presente na PNEA, em especial a atividade 4 (atividade náutica). Talvez, por suas características, tenha uma maior viabilidade para contemplar os princípios dados pela nossa legislação.

Além das contribuições trazidas por este trabalho quanto ao levantado com as observações, espera-se que o roteiro elaborado para o realizar possa contribuir com outras pesquisas que também busquem (em outras localidades, regiões, períodos e circunstâncias) respostas aos mesmos questionamentos levantados neste projeto. A aplicação do roteiro em outros momentos pode trazer 
outros resultados, e por isso valoriza-se seu uso enquanto ferramenta científica e metodológica.

Por fim, conclui-se que é possível observar um diálogo de questões ambientais dentro do recorte feito, apesar de nem todas as atividades abordarem o tema com a mesma intensidade ou mesmo equilíbrio entre os princípios da PNEA.

\section{Agradecimentos}

Aos professores Allan e Izabel, pela dedicada orientação. À professora Rosana Jammal pelas valorosas contribuições. Ao Grupo Escoteiro do Mar "Ilha do Mel", por ser minha segunda casa e me proporcionar tanto crescimento pessoal. À Tropa Escoteira "Tadami Sato", por me permitirem contemplar o potencial da educação não-formal. À minha mãe, pelo apoio incondicional.

\section{Referências}

BRASIL. Lei n 9795 de 27 de Abril de 1999. Política Nacional de Educação Ambiental, Brasília, DF. Disponível em: <.http://www.planalto.gov.br/ccivil 03/leis/L9795.htm>. Acesso em: 02 jan. 2018.

ESCOTEIROS DO BRASIL. Política Nacional de Programa Educativo. Curitiba, 2018.

ESCOTEIROS DO BRASIL. Princípios, Organização e Regras. Curitiba, 2013. ESCOTEIROS DO BRASIL. Projeto Educativo do Movimento Escoteiro. Curitiba, 2017.

ESCOTEIROS DO BRASIL. Relatório Anual 2017. Curitiba, 2018.

ESCOTEIROS DO BRASIL, Região do Paraná. Relatório Anual 2017. Curitiba, 2018.

MARCOMIN, F.E. Educação Ambiental: uma incursão na percepção ambiental e na sensibilização imagética. Rev. Eletrônica Mestrado em Educação Ambiental. E-ISSN 1517-1256, v. 31, n.2, p.106-126,, jul./dez. 2014. Disponível em: <https://periodicos.furg.br/remea/article/viewFile/4646/3083>. Acesso em: 17 jun. 2018.

NAGY, L. 250 milhões de Escoteiros. 2ª Edição. Genebra: The World Scout Foundation, 1985.

PAOLILLO, C. Educação Ambiental e Educação Científica no contexto do Movimento Escoteiro. Experiências em Ensino de Ciências, São Paulo, v. 4, n. 2, p. 93-105, 2009. Disponível em: <http://www.if.ufrgs.br/eenci/artigos/ Artigo ID84/v4 n2 a2009.pdf>. Acesso em: 02 de jan. de 2018. 


\title{
Apêndice 1 - Roteiro de Observação de Atividades Escoteiras \\ Roteiro de observação de atividades escoteiras
}

\author{
Atividade: \\ № de participantes: \\ Duração: \\ Material utilizado: \\ Descrição:
}

\begin{tabular}{|l|l|l|l|l|l|l|}
\hline \multirow{2}{*}{$\begin{array}{l}\text { Artigo da Política Nacional de Educação } \\
\text { Ambiental (Princípios/Objetivos contidos nos } \\
\text { Artigos 4 e 5) }\end{array}$} & \multicolumn{3}{l|}{ Presente em algum grau na atividade? } \\
\cline { 2 - 7 } & $\mathbf{0}$ & $\mathbf{1}$ & $\mathbf{2}$ & $\mathbf{3}$ & $\mathbf{4}$ & $\mathbf{5}$ \\
\hline $\begin{array}{l}\text { I - o enfoque humanista, holístico, democrático e } \\
\text { participativo; }\end{array}$ & & & & & & \\
\hline $\begin{array}{l}\text { II - a concepção do meio ambiente em sua } \\
\text { totalidade, considerando a interdependência entre o } \\
\text { meio natural, o sócio-econômico e o cultural, sob o } \\
\text { enfoque da sustentabilidade; }\end{array}$ & & & & & & \\
\hline $\begin{array}{l}\text { III - o pluralismo de idéias e concepções } \\
\text { pedagógicas, na perspectiva da inter, multi e } \\
\text { transdisciplinaridade; }\end{array}$ & & & & & & \\
\hline $\begin{array}{l}\text { IV - a vinculação entre a ética, a educação, o } \\
\text { trabalho e as práticas sociais; }\end{array}$ & & & & & & \\
\hline $\begin{array}{l}\text { V - a garantia de continuidade e permanência do } \\
\text { processo educativo; }\end{array}$ & & & & & & \\
\hline $\begin{array}{l}\text { VI - a permanente avaliação crítica do processo } \\
\text { educativo; }\end{array}$ & & & & & & \\
\hline $\begin{array}{l}\text { VII - a abordagem articulada das questões } \\
\text { ambientais locais, regionais, nacionais e globais; }\end{array}$ & & & & & & \\
\hline $\begin{array}{l}\text { VIII - o reconhecimento e o respeito à pluralidade e } \\
\text { à diversidade individual e cultural. }\end{array}$ & & & & & & \\
\hline
\end{tabular}

\section{Anotações:}

